\title{
Tehran Lipid and Glucose Study: A National Legacy
}

\author{
Fereidoun Azizi ${ }^{1, *}$ \\ ${ }^{1}$ Endocrine Research Center, Research Institute for Endocrine Sciences, Shahid Beheshti University of Medical Sciences, Tehran, Iran \\ "Corresponding author: Endocrine Research Center, Research Institute for Endocrine Sciences, Shahid Beheshti University of Medical Sciences, Tehran, Iran. Email: \\ azizi@endocrine.ac.ir \\ Received 2018 September 30; Accepted 2018 October 06.
}

Keywords: Tehran Lipid and Glucose Study, Non-Communicable Diseases, Cardiovascular Disease

The year 2018 marks 20 years since the landmark Tehran Lipid and Glucose Study (TLGS) was designed in a west-Asian developing country, the Islamic republic of Iran. With rapid economic and demographical transition in Iran in the last decades of the twentieth century(1), a dramatic risk in non-communicable diseases (NCDs), cardiovascular disease in particular, as the major cause of morbidity and mortality has occurred (2). In 1996, the National Network for Prevention and Management of Diabetes was designed and implemented as the first Iranian national project for prevention and control of NCDs (3).

In 1997, the National Supreme Council for Scientific Research called for national research projects in various scientific fields. Dr. Fereidoun Azizi, the director of Endocrine Research Center was persuaded by the late Dr. Sanei, the Vice-chancellor for Research of the Ministry of Health and Medical Education to design a proposal for survey aimed at identifying NCDs. Dr Azizi's proposal was extended to include a surveillance of a cohort for at least 20 - 30 years (4); his proposal was accepted as a national research project and his research team have described the baseline findings of TLGS in various articles, showing very high prevalence of cardio metabolic risk factors, including diabetes, hypertension and lipid profiles in the Tehranian population.

Periodic examinations and follow up of over 15000 individuals, 3 - 80 years of age, every 3 years was a great opportunity to determine the trend of various risk factors of the TLGS population in a country in nutrition transition with substantial changes in life style (5). Continuation of a cohort study, especially in a developing country is a major challenge; lack of infrastructure, influence of various factors such as culture, economy, education, and social behaviors, are the major barriers for such study. This is why many surveys are often performed to determine risk factors in populations at a particular point of time, while surveillance, systematic collection, analysis and interpretation of health data in a periodic fashion, with appropriate feedback to policymakers, is lacking in developing countries (6).

In the TLGS, following the collection of baseline data, an ongoing community-oriented life style change is being implemented. This intervention has been effective in decreasing the incidence of type 2 diabetes (7) and in diminishing the prevalence of metabolic syndrome and its components (8). Therefore, TLGS has added the aspect of "intervention" for health benefits, which has been lacking in many cohort studies, such as the Framingham heart study (9).

Inclusion of children and adolescents in the cohort of TLGS has allowed researchers to evaluate, nutrition, demographic and risk factor trends from early childhood, through adolescence into adult life. Studying these trends would be helpful to plan lifestyle and other interventions to prevent progression of risk factors to established disease in adulthood (10).

More recently, TLGS has conducted studies involving genomics and the biomarkers of NCDs and has performed the first whole-genome sequencing and launch the Iranian Reference Genome Research Project (11). Having informations on the genomes and metabolomics of this cohort with 20 years of phenotypic data could disclose many aspects of personalized medicine in endocrinology and other domains of medicine (12).

This issue of the International Journal of Endocrinology and Metabolism is dedicated to celebrating the legacy of the TLGS. We asked the researchers involved in the design, implementation, analysis, and data description and interpretation of the TLGS, to describe the key contributions of TLGS in the identification of health issues related to NCDs in the past 20 years. The authors of this special issue collectively have contributed more than 900 peerreviewed publications related to the TLGS. We hope these 
articles would be beneficial for surveys and surveillances of NCDs in the world and in particular, in developing countries.

\section{References}

1. Ghassemi H, Harrison G, Mohammad K. An accelerated nutrition transition in Iran. Public Health Nutr. 2002;5(1A):149-55. doi: 10.1079/PHN2001287. [PubMed: 12027278].

2. Sarrafzadegan N, Najafian J. Priorities in cardiovascular prevention in Iran. Iran Heart J. 1998;1(1):131.

3. Azizi F, Gouya MM, Vazirian P, Dolatshahi P, Habibian S. The diabetes prevention and control programme of the Islamic Republic of Iran. East Mediterr Health J. 2003;9(5-6):1114-21. doi: 10.1007/s000380200008. [PubMed: 16450545].

4. Azizi F, Rahmani M, Emami H, Mirmiran P, Hajipour R, Madjid M, et al. Cardiovascular risk factors in an Iranian urban population: Tehran lipid and glucose study (phase 1). Soz Praventivmed. 2002;47(6):40826. [PubMed: 12643001].

5. Azizi F, Ghanbarian A, Momenan AA, Hadaegh F, Mirmiran P, Hedayati $\mathrm{M}$, et al. Prevention of non-communicable disease in a population in nutrition transition: Tehran Lipid and Glucose Study phase II. Trials. 2009;10:5. doi: 10.1186/1745-6215-10-5. [PubMed: 19166627]. [PubMed Central: PMC2656492].

6. Azizi F. Tehran lipid and glucose study: A legacy for prospective community-based research. Arch Iran Med. 2014;17(6):392-3. [PubMed: 24916522].
7. Harati H, Hadaegh F, Momenan AA, Ghanei L, Bozorgmanesh MR, Ghanbarian A, et al. Reduction in incidence of type 2 diabetes by lifestyle intervention in a middle eastern community. Am J Prev Med. 2010;38(6):628-636 e1. doi: 10.1016/j.amepre.2010.03.003. [PubMed: 20494239].

8. Azizi F, Mirmiran P, Momenan AA, Hadaegh F, Habibi Moeini A, Hosseini $F$, et al. The effect of community-based education for lifestyle intervention on the prevalence of metabolic syndrome and its components: tehran lipid and glucose study. Int J Endocrinol Metab. 2013;11(3):145-53. doi: 10.5812/ijem.5443. [PubMed: 24348586]. [PubMed Central: PMC3860109].

9. Wong ND, Levy D. Legacy of the framingham heart study: Rationale, design, initial findings, and implications. Glob Heart. 2013;8(1):3-9. doi:10.1016/j.gheart.2012.12.001. [PubMed: 25690260].

10. Mirbolouk M, Derakhshan A, Charkhchi P, Guity K, Azizi F, Hadaegh F. Incidence and predictors of early adulthood pre-diabetes/type 2 diabetes, among Iranian adolescents: The Tehran Lipid and Glucose Study. Pediatr Diabetes. 2016;17(8):608-16. doi: 10.1111/pedi.12343. [PubMed: 26764014].

11. Daneshpour MS, Fallah MS, Sedaghati-Khayat B, Guity K, Khalili D, Hedayati M, et al. Rationale and design of a genetic study on cardiometabolic risk factors: Protocol for the Tehran Cardiometabolic Genetic Study (TCGS). JMIR Res Protoc. 2017;6(2). e28. doi: 10.2196/resprot.6050. [PubMed: 28232301]. [PubMed Central: PMC5344981].

12. Azizi F. Precision medicine for endocrinology. Int J Endocrinol Metab. 2016;14(3). e40283. doi: 10.5812/ijem.40283. [PubMed: 28115967]. [PubMed Central: PMC5219894]. 